\title{
Obtaining Luminous Phosphate Coatings on Steel by Cold Method
}

\author{
Viktoriya S. Konovalova ${ }^{1, a^{*}}$ and Varvara E. Rumyantseva ${ }^{1, b}$
}

${ }^{1}$ Ivanovo State Polytechnic University, department of natural sciences and technosphere safety, 153000, Sheremetevsky av., 21, Ivanovo, Russian Federation

akotprotiv@yandex.ru, bvarrym@gmail.com

Keywords: Protective Coatings, Phosphate Coatings, Protection of Steel, Cold Phosphating, Color Phosphating, Luminous Coatings

\begin{abstract}
The possibility of obtaining luminous phosphate coatings on steel by cold method has been studied. Modified cold phosphating solutions containing organic additives (glycerin, trilon $\mathrm{B}$, OS-20 emulsifier) were selected as the basis to maintain the $\mathrm{pH}$, stabilize the solution and improve the quality and structure of the deposited coatings. To obtain the glow effect, a green phosphor based on $\mathrm{Zn}_{2} \mathrm{SiO}_{4}$ containing manganese as a sensitizer was added to the phosphating solution. During deposition, phosphate coatings are obtained that glow with spots, but constant mixing of the solution during deposition contributes to the uniform distribution of phosphor in the phosphate film. Luminous phosphate coatings have good protective properties, they can be used as an independent protection of steel surfaces from corrosion.
\end{abstract}

\section{Introduction}

All conventional phosphating solutions are based on dilute phosphoric acid solutions based on alkaline or heavy metal ions, which mainly contain free phosphoric acid and primary phosphates of metal ions [1-4]. When a steel product is introduced into a phosphating solution, a topochemical reaction occurs in which the dissolution of iron is initiated by free phosphoric acid on microanodes present on the surface of the steel $[5,6]$. Hydrogen is released on microcathode areas of the surface:

$$
\mathrm{Fe}+2 \mathrm{H}_{3} \mathrm{PO}_{4} \rightarrow \mathrm{Fe}\left(\mathrm{H}_{2} \mathrm{PO}_{4}\right)_{2}+\mathrm{H}_{2}
$$

The formation of soluble primary ferrous phosphate leads to simultaneous local depletion of the concentration of free acid in the solution, leading to an increase in $\mathrm{pH}$ at the «metal - solution» interface. This change in $\mathrm{pH}$ shifts the hydrolytic equilibrium that exists between soluble primary phosphates and insoluble tertiary phosphates of metal ions present in the phosphating solution, which leads to rapid conversion and deposition of insoluble tertiary metal phosphates [7-9]. In a zinc phosphate bath, these equilibria can be represented as [10]:

$$
\begin{gathered}
\mathrm{Zn}\left(\mathrm{H}_{2} \mathrm{PO}_{4}\right)_{2} \leftrightarrow \mathrm{ZnHPO}_{4}+\mathrm{H}_{3} \mathrm{PO}_{4} \\
3 \mathrm{Zn}\left(\mathrm{H}_{2} \mathrm{PO}_{4}\right)_{2} \leftrightarrow \mathrm{Zn}_{3}\left(\mathrm{PO}_{4}\right)_{2}+2 \mathrm{H}_{3} \mathrm{PO}_{4}
\end{gathered}
$$

A certain amount of free phosphoric acid must be present in order to suppress hydrolysis and maintain the stability of the bath for effective precipitation of phosphates on microcathode areas of the metal surface [11-13].

The composition of the phosphating solution and the concentration of its components determine the nature of the coatings formed [14]. The color of the traditional phosphate coating can be from 
light gray to gray, depending on the material and pre-treatment of the surface of the phosphated product $[15,16]$. The development of phosphate films of colors other than gray is of particular interest. Luminous phosphate coatings with good anti-corrosion and performance characteristics can be used to protect metal structures, fences, pillars.

\section{Materials and Methods}

In order to obtain luminous phosphate coatings, a green luminophor based on $\mathrm{Zn}_{2} \mathrm{SiO}_{4}$ containing manganese as a sensitizer was introduced into modified cold phosphating solutions (Table 1) [15] at the rate of $20 \mathrm{~g} / \mathrm{l}$. Luminophors are synthetic substances capable of converting various types of energy into light, that is, luminescent $[17,18]$.

Table 1. Composition of modified solution for cold phosphating of iron-carbon alloys

\begin{tabular}{|c|c|}
\hline Components & Ammount [g/l] \\
\hline «Majef» Zn(NO$\left._{3}\right)_{2}$ & $35-45$ \\
$\mathrm{NaNO}_{2}$ & $50-65$ \\
Glycerin & $3-4$ \\
Trilon 5 & $1-2$ \\
Emulsifier OS-20 & $6-8$ \\
\hline
\end{tabular}

Coatings from solutions containing luminophor were deposited on samples of steel grade St3 (the chemical composition of steel is shown in Table 2). The surface of the samples is pre-sanded, degreased and etched.

Table 2. Chemical composition of steel samples

\begin{tabular}{|c|c|c|c|c|c|c|c|c|c|c|c|}
\hline Components & $\mathrm{C}$ & $\mathrm{Si}$ & $\mathrm{Mn}$ & $\mathrm{Ni}$ & $\mathrm{S}$ & $\mathrm{P}$ & $\mathrm{Cr}$ & $\mathrm{N}$ & $\mathrm{Cu}$ & $\mathrm{As}$ & $\mathrm{Fe}$ \\
\hline \multirow{2}{*}{ Ammount [\%] } & $0,14-$ & $0,15-$ & $0,4-$ & up to & up to & up to & up to & up to & up to & up to & \multirow{2}{*}{ (157 } \\
& 0,22 & 0,3 & 0,65 & 0,3 & 0,05 & 0,04 & 0,3 & 0,008 & 0,3 & 0,08 & \\
\hline
\end{tabular}

The samples were hung in a container with a solution placed in a thermostat (Fig. 1). The deposition of the coating was carried out at a temperature of $30{ }^{\circ} \mathrm{C}$.

The precipitated phosphate films were developed in the rays of an ultraviolet lamp.

The protective ability of oxide-phosphate films was determined by the drop method. As an indicator, a solution containing $\mathrm{CuSO}_{4} \cdot 5 \mathrm{H}_{2} \mathrm{O} 80 \mathrm{~g} / \mathrm{l}, \mathrm{NaCl} 33 \mathrm{~g} / 1, \mathrm{HCl}(0,1 \mathrm{~N}) 13 \mathrm{ml} / 1$ was used. A drop of the solution was applied to a surface covered with a phosphate film, and after turning on the stopwatch, its color was monitored, which changed from blue to red. If at $15-20{ }^{\circ} \mathrm{C}$ on a steel sample with a phosphate film free of organic substances, the color change occurred earlier than 2 minutes, then the protective ability of the film was considered low, at 2-5 minutes - average, longer than 5 minutes - high. When tested under a drop of reagent, the release of the smallest particles of metallic copper was sometimes observed. This phenomenon, if it was not accompanied by a drop change, was not taken into account when assessing the corrosion resistance of the phosphate coating.

To calculate the speed and characteristics of the metal corrosion process, polarization diagrams are constructed graphically: $\varphi_{\mathrm{a}}-i_{\mathrm{a}}-$ the curve of anodic polarization of the anode areas of the metal surface and $\varphi_{\mathrm{k}}-i_{\mathrm{k}}$ - the curve of cathodic polarization of the cathodic areas of the metal surface. The analysis of the constructed corrosion diagrams consists in determining the controlling 
process, i.e. the stage of the process of electrochemical corrosion of the metal, which has the greatest resistance compared to other stages. For the highest value of the achieved current on corrosion diagrams, corrosion rate indicators are calculated.

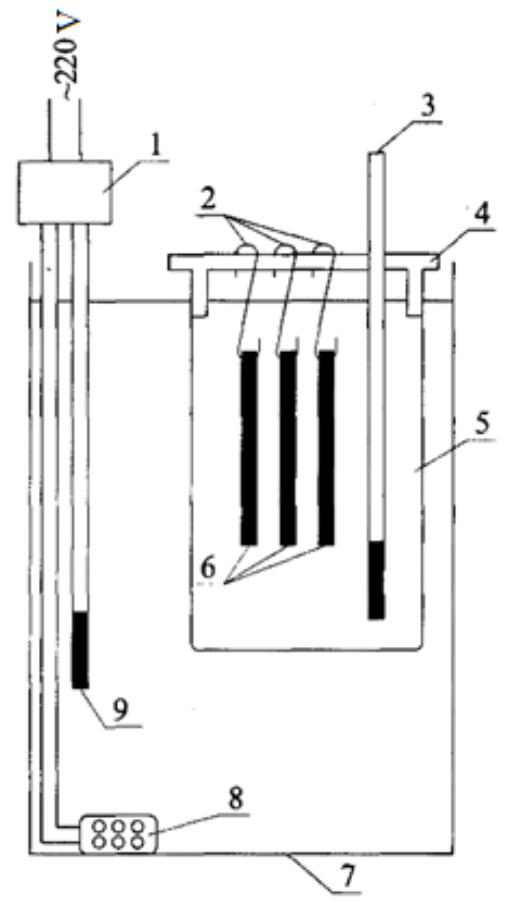

Fig. 1. Scheme of the deposition device: 1 - 1 -electronic relay; 2 - glass hooks for hanging samples; 3 - thermometer; 4 - rod; 5 - glass vessel with electrolyte (0.1 $\mathrm{N} \mathrm{H}_{2} \mathrm{SO}_{4}$ solution); 6 test samples; 7 -water thermostat; 8 -electric heater; 9 -contact thermometer.

\section{Results and Discussion}

As can be seen in Fig. 2-a, phosphate coating with luminophor glows unevenly and is not bright enough, so it was proposed to carry out precipitation with constant stirring of the solution. The luminophor in the phosphate coating, when the solution is mixed, is distributed more evenly over the surface of the sample and glows brighter when developed under ultraviolet light (Fig. 2-b).

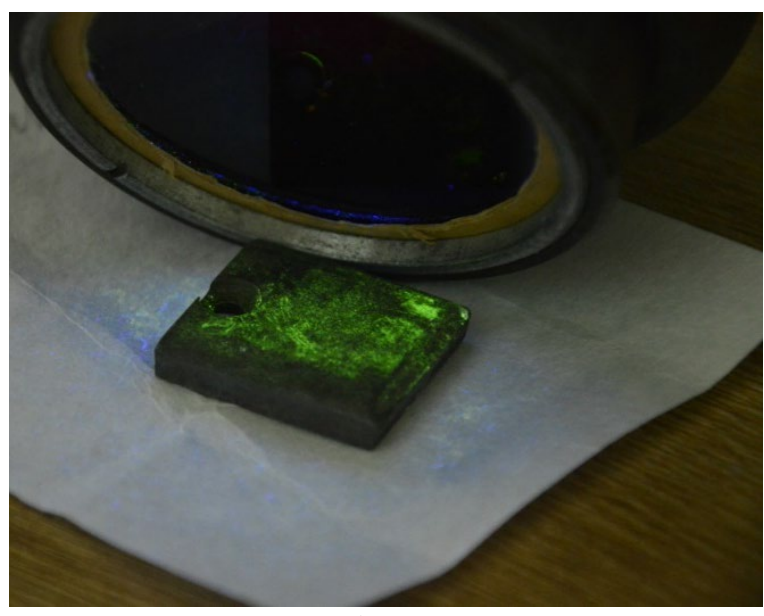

a)

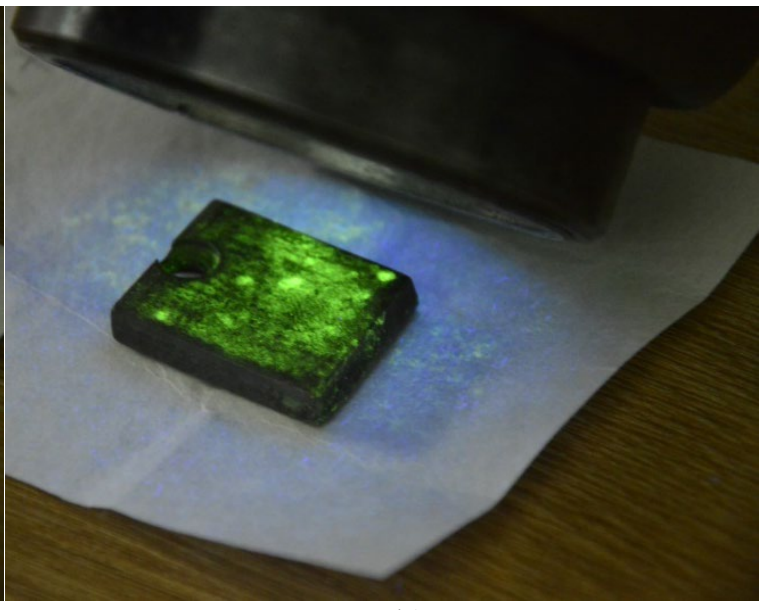

b)

Fig. 2. Luminous phosphate coatings: $a$-coating obtained without mixing the solution; $b-$ coating obtained by mixing the solution 
Tests of coatings for corrosion protection by the drip method have shown that the resulting luminous coating has similar protective properties with modified phosphate coatings without luminophor [19, 20] (Table 3).

Table 3. Results of testing of steel samples with phosphate coating by drip method

\begin{tabular}{|c|c|c|}
\hline \multirow{2}{*}{ Test time, sec } & \multicolumn{2}{|c|}{ Type of coating } \\
\cline { 2 - 3 } & Modified & Luminous \\
\hline $\begin{array}{c}\text { Control time immediately } \\
\text { after phosphating }\end{array}$ & 135 & 137 \\
\hline Control time after 24 hours & 375 & 360 \\
\hline
\end{tabular}

By the method of contact corrosion, data were obtained to determine the corrosion rate of steel samples with phosphated coatings (Table 4). The coating obtained from a solution with the addition of luminophor is not inferior in protective properties to the modified phosphate coating.

Table 4. Corrosion rate of steel samples protected by phosphate coatings in $10 \% \mathrm{NaCl}$ solution, $g /\left(m^{2} h\right)$

\begin{tabular}{|c|c|}
\hline $\begin{array}{c}\text { Coating without the } \\
\text { additive }\end{array}$ & $\begin{array}{c}\text { Coating with } \\
\text { luminophor additive }\end{array}$ \\
\hline 0,614 & 0,623 \\
\hline
\end{tabular}

The results obtained indicate that luminous phosphate coatings can be used as an independent protection of steel products from corrosion.

\section{Summary}

Obtaining luminous phosphate coatings at room temperature is possible with constant stirring of the solution. In this case, the luminophor introduced into the phosphating solution is evenly distributed in the deposited film, resulting in a uniform glow of the phosphate coating. Phosphate coatings obtained at room temperature have good quality and high protective properties.

\section{References}

[1] D.B. Freeman, Phosphating and metal pretreatment: A guide to mod. processes a. practice, Cambridge: Woodhead - Faulkner in assoc. with Pyrene chem. services, 1986, IX, 229 p.

[2] W. Rausch, The Phosphating of Metals, London: Finishing Publications Ltd., 1990, 416 p.

[3] G. Lorin, Phosphating of Metals, London: Finishing Publications, 1974, 229 p.

[4] V.N. Selivanov, Yu.P. Perelygin, The universal phosphating solution, University proceedings. Volga region. Natural sciences. 1 (1) (2013) 135-143.

[5] C.-C. Jiang, G.-Y. Xiao, X. Zhang, R.-F. Zhu, Y.-P. Lu, Formation and corrosion resistance of a phosphate chemical conversion coating on medium carbon low alloy steel, New Journal of Chemistry. 40 (2) (2016) 1347-1353. https://doi.org/10.1039/C5NJ02245B

[6] F. Zucchi, G. Tranbelli, Anodic behaviour of Fe in phosphate solutions, Corrosion Science. 11 (3) (1971) 141-151. https://doi.org/10.1016/S0010-938X(71)80090-2 
[7] C. Jiang, Z. Gao, H. Pan, X. Cheng, The initiation and formation of a double-layer phosphate conversion coating on steel, Electrochemistry Communications. 114 (2020) 106676.

https://doi.org/10.1016/j.elecom.2020.106676

[8] T.S.N. Sankara Narayanan, Surface pretreatment by phosphate conversion coatings - a review, Reviews on advanced materials science. 9 (2) (2005) 130-177.

[9] I.Ya. Kiselev, Formation of a phosphate coating on carbon steel, Protection of Metals. 26 (2) (1990) 215-218.

[10] D. Ivanova, Phosphatazing of mild steel in zinc-manganese-nickel phosphates in different correlations, Journal of Chemical Technology and Metallurgy. 54 (5) (2019) 1072-1078.

[11] T.K. Akaeva, O.P. Akaev, O.N. Rodin, E.A. Naiman, Steel products phosphating with compositions based on phosphoric acid, Vestnik of Kostroma State University. 4 (2013) 8-12.

[12] A.G. Orlov, I.G. Antonova, N.N. Grechishkin, Rapid, low-temperature phosphating of steel items for consumer goods, Protection of metals. 34 (1) (1998) 62-65.

[13] Gh. Barati Draband, M. Liofkhazraei, Electrochemical phosphate conversion coating: a review, Surface review and letters. 24 (3) (2017) 1730003.

https://doi.org/10.1142/S0218625X17300039

[14] G. Górecki, Iron phosphate coatings - composition and corrosion resistance, Corrosion. 48 (7) (1992) 613-616. https://doi.org/10.5006/1.3315980

[15] V.S. Konovalova, V.E. Rumyantseva, Production of colored phosphate coatings on steel, Materials Science Forum. 1037 (2021) 457-463.

https://doi.org/10.4028/www.scientific.net/MSF.1037.457

[16] F. Gao, Z. Xiong, H. Xue, Y. Liu, Improved performance of strontium aluminate luminous coating on the ceramic surface, Journal of Physics Conference Series. 152 (1) (2009) 012082. https://doi.org/10.1088/1742-6596/152/1/012082

[17] L. Liu, X.F. Yan, Z.M. Zhang, L.M. Yu, Novel Functional Coating: Luminescent Coating, Advanced Materials Research. 337 (2011) 37-40.

https://doi.org/10.4028/www.scientific.net/AMR.337.37

[18] M.N. Getz, P.-A. Hansen, H. Fjellvåg, O. Nilsen, Luminescent properties of europium titanium phosphate thin films deposited by atomic layer deposition, RCS Advances. 7 (13) (2017) 8051-8059. https://doi.org/10.1039/C6RA27644J

[19] L. Fedrizzi, F. Deflorian, S. Rossi, L. Fambri, P.L. Bonora, Study of the corrosion behaviour of phosphatized and painted industrial water heaters, Progress in Organic Coatings. 42 (1-2) (2001) 65-74. https://doi.org/10.1016/S0300-9440(01)00153-9

[20] V.S. Konovalova, V.E. Rumyantseva, Corrosion Protection of Reinforcement with Phosphate Coatings, IOP Conference Series: Materials Science and Engineering. 890 (2020) 012091. https://doi.org/10.1088/1757-899X/890/1/012091 